\title{
Influence of urban land cover changes and climate change for the exposure of European cities to flooding during high-intensity precipitation
}

\author{
P. Skougaard Kaspersen ${ }^{1}$, N. Høegh Ravn ${ }^{2}$, K. Arnbjerg-Nielsen ${ }^{3}$, H. Madsen ${ }^{4}$, and M. Drews ${ }^{1}$ \\ ${ }^{1}$ Climate Change and Sustainable Development group, Department of Management Engineering, Technical \\ University of Denmark, Frederiksborgvej 399, building 110, 4000 Roskilde, Denmark \\ ${ }^{2}$ LNH Water, Skelbækgade 38 3th, 1717 Copenhagen V, Denmark \\ ${ }^{3}$ Department of Environmental Engineering, Technical University of Denmark, Miljøvej, Building 114, \\ 2800 Kgs. Lyngby, Denmark \\ ${ }^{4}$ DHI, Agern Allé 5, 2970 Hoersholm, Denmark
}

Correspondence to: P. Skougaard Kaspersen (pskk@dtu.dk)

Received: 11 March 2015 - Accepted: 11 March 2015 - Published: 11 June 2015

\begin{abstract}
The extent and location of impervious surfaces within urban areas due to past and present city development strongly affects the amount and velocity of run-off during high-intensity rainfall and consequently influences the exposure of cities towards flooding. The frequency and intensity of extreme rainfall are expected to increase in many places due to climate change and thus further exacerbate the risk of pluvial flooding. This paper presents a combined hydrological-hydrodynamic modelling and remote sensing approach suitable for examining the susceptibility of European cities to pluvial flooding owing to recent changes in urban land cover, under present and future climatic conditions. Estimated changes in impervious urban surfaces based on Landsat satellite imagery covering the period 1984-2014 are combined with regionally downscaled estimates of current and expected future rainfall extremes to enable 2-D overland flow simulations and flood hazard assessments. The methodology is evaluated for the Danish city of Odense. Results suggest that the past 30 years of urban development alone has increased the city's exposure to pluvial flooding by $6 \%$ for 10 -year rainfall up to $26 \%$ for 100-year rainfall. Corresponding estimates for RCP4.5 and RCP8.5 climate change scenarios (2071-2100) are in the order of 40 and $100 \%$, indicating that land cover changes within cities can play a central role for the cities' exposure to flooding and conversely also for their adaptation to a changed climate.
\end{abstract}

\section{Introduction}

The intensified urbanisation caused by rapid population growth and increasing rural migration is in many studies found to be a major cause of amplified peak flows and increased flood risk in cities worldwide (Chang and Franczyk, 2008). Changes in the urban land cover are important factors for the increased susceptibility to flooding. Thus, the increasing presence and location of impervious surfaces (IS) like roads, buildings, parking lots and other paved areas strongly affect the amount and velocity of run-off during high-intensity precipitation events (Arnold and Gibbons, 1996). Climate change is expected to exacerbate the flood risk as heavy precipitation is projected to increase in intensity and frequency over many areas of the globe, including central, northwest and northern Europe (Field et al., 2012; EU and EEA, 2012).

Most major cities in Europe are characterized by IS fractions ranging from $50-75 \%$ or even higher (EU and EEA, 2012). If present trends towards increasing IS fractions continues this is expected to further aggravate the risk of pluvial flooding. On the other hand the introduction of more pervious surfaces could serve as adaptation to climate change. Hence, detailed knowledge of the importance of both urban land cover changes and climate change for the risk of urban areas towards flooding provides substantial insight into how 

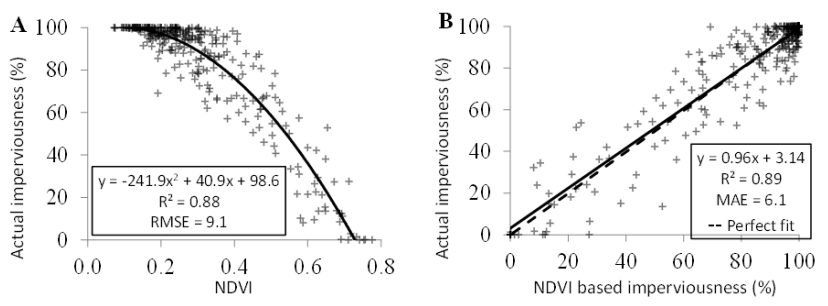

Figure 1. Relationship between NDVI and actual imperviousness for sample area (a), and relationship between NDVI based imperviousness and NDVI based imperviousness for sample area (b). RMSE $=$ Root Mean Squared Error, MAE $=$ Mean Absolute Error.

to plan for future climate proof cities. Simulations of urban flooding based on more or less detailed hydrodynamic models are commonplace most places in Europe, where they are used for e.g. urban drainage design and/or emergency management purposes. Some of these studies take climate change into account, whereas others consider past, present or future urban development. Integrated maps at the European level (EU and EEA, 2012) or even at the country level are, however, not readily available due to these significant differences in modelling approaches and tools.

In this paper we present a methodology suitable for investigating the relative and combined influence of historical urban land cover changes and climate change for the exposure of cities to pluvial flooding. The combined remote sensing and flood modelling approach enables the quantification of the flood risk relative to changes in imperviousness and climate change. The methodology is validated using data from the Danish city of Odense, comparing the influence of the past 30 years (1984-2014) of urban land cover changes on the exposure to flooding under present day conditions and future climate conditions. The method is, however, easily applicable for the majority of cities in Europe.

\section{Methods and materials}

\subsection{Urban land cover change}

Estimated changes in IS during the period 1984-2014 may generally be derived from analyses of Landsat moderate resolution $(30 \mathrm{~m})$ satellite imagery, assuming a relationship between the vegetation cover and the fraction of IS in the urban environment (Bauer et al., 2008; Skougaard Kaspersen et al., 2015). A regression model was developed for the city of Odense using the Normalized Difference Vegetation Index (NDVI) as a measure of green vegetation while IS were manually digitized from a high-resolution aerial photography (Fig. 1). To exclude major areas characterized by bare soil, which are spectrally similar to man-made impervious surfaces, the city's boundary was established prior to the analysis. Inside the city boundary urban areas are implicitly assumed to consist of a combination of impervious surfaces and green vegetation and only marginally by areas of bare soil. Random training and validation areas of approximately $500 \mathrm{~m} \times 500 \mathrm{~m}$ (314 Landsat pixels) covering the full range of IS values were chosen for the development and validation of the regression model. A non-linear function was found to best describe the relationship between NDVI and IS fractions (Root Mean Squared Error $=9.1 \%$ ) and to provide the basis for the most accurate estimate of IS fractions based on NDVI (Mean Average Error $=6.1 \%$ ) (Fig. 1). For the current analysis the city boundary was digitized manually from the 2014 Landsat imagery and used as delineator of the urban area for both 1984 and 2014.

\subsection{Projections of extreme precipitation}

High resolution climate projections for precipitation extremes may be derived from global coupled atmosphereocean circulation models (GCMs) and downscaled using regional climate models (RCMs) and/or empirical-statistical approaches (Willems, 2012). To assert the considerable uncertainties associated with future projections of changes in the frequency and intensity of extreme events, such projections are generally based on multi-model ensembles (van der Linden and Mitchell, 2009) rather than single model projections, combined with different statistical downscaling methods (Gregersen et al., 2013; Sunyer et al., 2014). Design intensities and "climate factors" (i.e. the ratio between the expected future and present design rainfall) for extreme precipitation in Denmark under present and future conditions have previously been estimated from regional climate projections (Gregersen et al., 2013). Here we use recent results from the "RiskChange" project (Maule et al., 2014; Arnbjerg-Nielsen et al., 2015) to generate 15 different time series for design precipitation, each with a duration of $4 \mathrm{~h}$ and representing precipitation events from 5 to 100 year return values, using a Chicago Design Storm (CDS) rain calculator (IDA, 2014) (Table 1) for corresponding present-day and future climate conditions (2071-2100; RCP4. and RCP8.5; Meinshausen et al., 2011). Initially, synthetic precipitation events based on statistical analyses of observed precipitation from approximately 300 precipitation gauges in Denmark were created for the specific geographical area of interest (Odense) (ArnbjergNielsen et al., 2006). Precipitation intensities from the CDS rain time series under current climate conditions were then multiplied by a CF to obtain corresponding intensities under RCP4.5 and RCP8.5 climate change scenarios (Table 1).

\subsection{Flood modelling}

When modelling overland flooding several modelling concepts are available. Some methods integrate 1-D modelling of flow in the sewage system with a 1-D description of overland flow (Maksimović et al., 2009) while others use modified software originally intended for estuarine and coastal modelling to interact with the drainage system, e.g. MIKE 
Table 1. Design intensities and climate factors for extreme precipitation in Odense under current and future climate, RP5 = return period of 5 years. CF's for RCP4.5 from Gregersen et al. (2014) and RCP 8.5 from Arnbjerg-Nielsen et al. (2015).

\begin{tabular}{llllll}
\hline & RP100 & RP50 & RP20 & RP10 & RP5 \\
\hline Current climate & & & & & \\
\hline Total precipitation $(\mathrm{mm})$ & 59 & 51 & 42 & 35 & 30 \\
Maximum intensity $\left(\mathrm{mm} \mathrm{h}^{-1}\right)$ & 43 & 37 & 29 & 25 & 21 \\
\hline RCP 4.5 & & & & & \\
\hline Climate factor & 1.6 & 1.4 & 1.29 & 1.22 & 1.2 \\
Total precipitation $(\mathrm{mm})$ & 83 & 66 & 51 & 42 & 33 \\
Maximum intensity $\left(\mathrm{mm} \mathrm{h}{ }^{-1}\right)$ & 60 & 47 & 36 & 30 & 23 \\
\hline RCP 8.5 & & & & & \\
\hline Climate factor & 2.2 & 1.98 & 1.84 & 1.8 & 1.6 \\
Total precipitation $\left(\mathrm{mm}^{2}\right.$ & 130 & 101 & 77 & 64 & 48 \\
Maximum intensity $\left(\mathrm{mm} \mathrm{h}^{-1}\right)$ & 94 & 72 & 54 & 44 & 33 \\
\hline
\end{tabular}
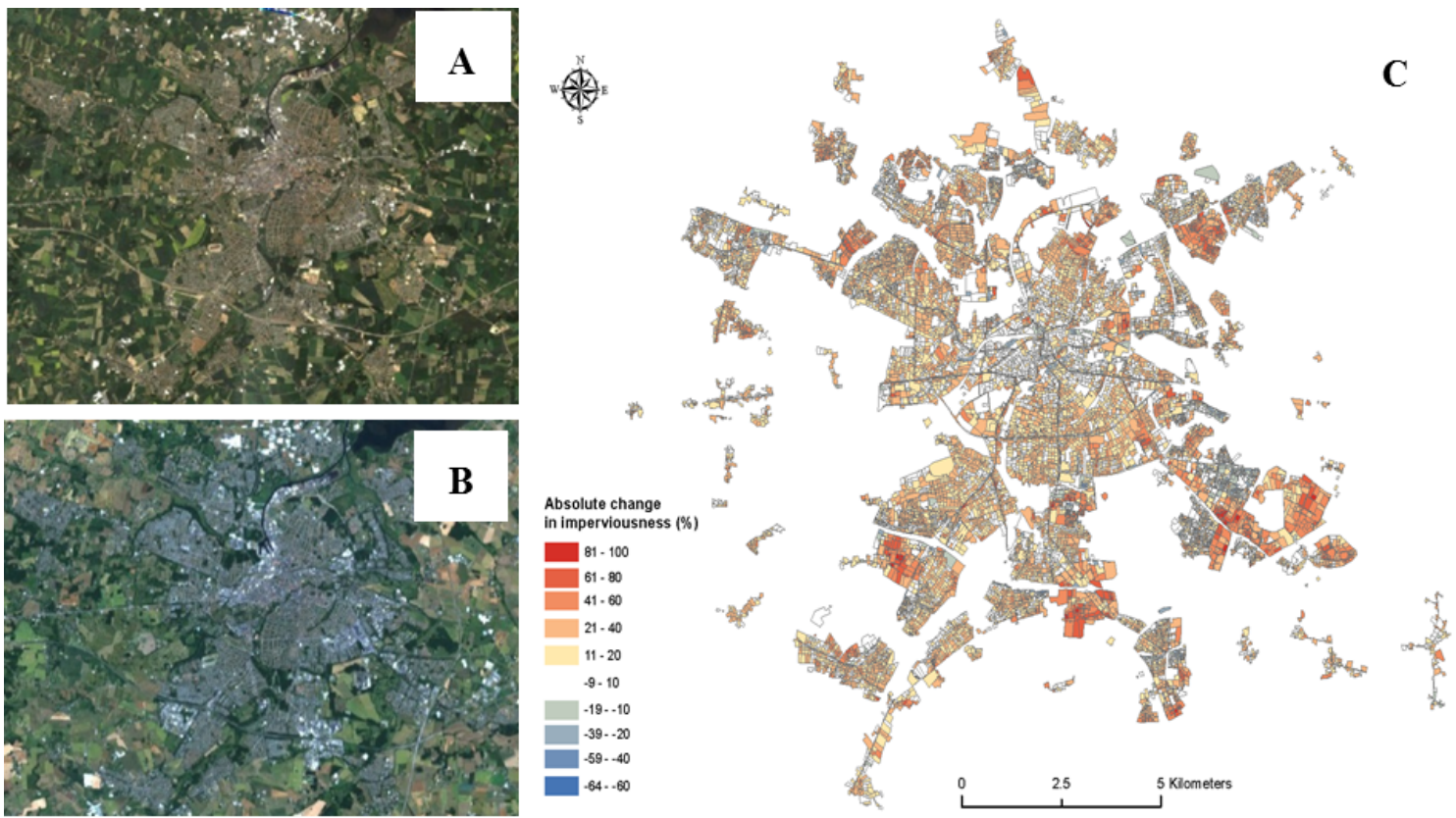

Figure 2. Landsat TM image Odense 1984 (a), Landsat OLI image Odense 2014 (b), Absolute change in imperviousness in Odense during the 1984-2014 period (c).

FLOOD (MIKE by DHI, 2014) or TUFLOW (TUFLOW, 2014). Pros and cons of these methods have been widely discussed and choice of method depend on the aim of the study, e.g. 1-D solutions are fast but offers a poor approximation of complex (non-unidirectional) flows (Mark et al., 2004; Leandro et al., 2009). When limited information of the drainage system is available it can be necessary to neglect the interaction with subsurface flows and model the overland flow by use of 2-D software and a digital elevation map (DEM) only. The current research uses such an approach as the occurrence of extreme precipitation is simulated using the 2-D hydrodynamic overland flow model in MIKE 21 (MIKE by DHI, 2014). The drainage capacity of the pipes is modelled by modifying the precipitation, e.g. by assuming a max pipe capacity and then subtracting the volume from the rain input. In order to include the effect of the drainage system it is assumed that it is dimensioned perfectly according to the current Danish recommendations. This means that flooding on terrain does not occur for precipitation with a return period of 5 years (RP5) or less. As a result we reduced all design precipitation time series with the amount of a 5-year event (RP5) prior to running the flood model simulations. Varia- 


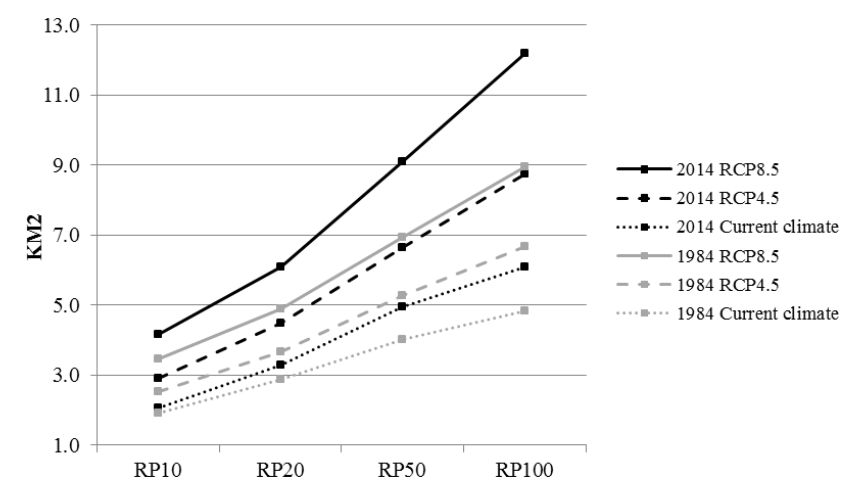

Figure 3. Total area flooded by $>10 \mathrm{~cm}$ of surface water during high-intensity precipitation events for present (2014) and historical (1984) land cover conditions and for current climate and RCP85, $1984=$ imperviousness of $32 \%, 2014=$ imperviousness of $51 \%$.

tion in run-off from areas with different levels of imperviousness is modelled by use of the evapotranspiration module in MIKE 21. Evapotranspiration is set to equal precipitation for pervious surfaces ( $0 \% \mathrm{IS}=0 \%$ run-off) while no evapotranspiration is assumed for completely sealed surfaces $(100 \%$ IS $=100 \%$ run-off). The EU-DEM (EU-DEM, 2014), which is publicly available over most of the European continent and has a spatial resolution of $25 \mathrm{~m}$ is used as input for the MIKE 21 model and provides the basis for the overland flow calculations. The Landsat based impervious surface maps are resampled from its original resolution $(30 \mathrm{~m})$ to match that of the EU-DEM ( $25 \mathrm{~m}$ ) as this is a requirement for the model to run.

\subsection{Influence of urban land cover changes and climate change on the exposure of cities to pluvial flooding}

The combined impact of changes in the urban land cover and climate change towards the exposure of Odense to pluvial flooding is investigated by simulating the occurrence of 5 distinctive high-intensity precipitation events (RP5, RP10, RP20, RP50, RP100) under both current and future climate (RCP4.5, RCP 8.5) and for historical (1984) and current (2014) urban land cover. The RCP4.5 scenario represent a fairly modest climate future with increases in the nearsurface air temperature towards 2100 in the range of $1.8^{\circ} \mathrm{C}$ $\left(1.1-2.6^{\circ} \mathrm{C}\right)$ compared to the pre-industrial (IPCC, 2013). Correspondingly, the RCP8.5 scenario represent a world where the increased radiative forcing corresponds to an increase in near-surface air temperature of $3.7^{\circ} \mathrm{C}\left(2.6-4.8^{\circ} \mathrm{C}\right)$ in the year 2100 . The primary outputs of the flood model are maps showing the maximum flood depth and extent for each individual simulation. A pairwise cross-comparison of the multiple flood maps enables a quantification of the relative importance of land cover changes as compared to climate change for the overall flood exposure from different highintensity precipitation events.

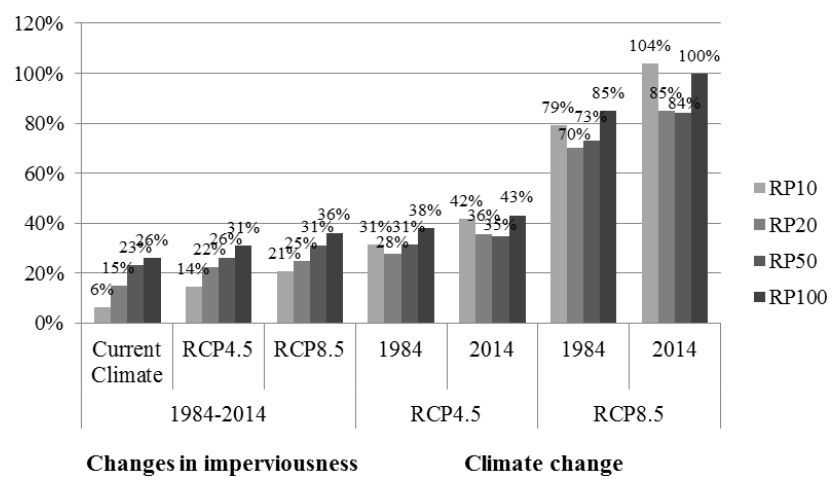

Figure 4. Effect of changes in imperviousness during 1984-2014 $(32 \rightarrow 51 \%)$ for current climate and in a RCP4.5 and RCP8.5 world, and impacts of climate change (RCP4.5, RCP8.5) for urban land cover as in 1984 (32\% IS) and 2014 (51\% IS) for total area flooded with $>10 \mathrm{~cm}$ of surface water during high-intensity precipitation.

\section{Results}

\subsection{Land cover changes during 1984-2014}

An urban land cover change analysis for Odense based on remote sensing estimates shows an overall increase in absolute imperviousness of $19 \%$, from $32 \%$ in 1984 to $51 \%$ in 2014 (Fig. 2c). There is a somewhat clear pattern that the majority of the sealing occurred at the fringes of the city during this period while the central parts are characterized by little or no change (Fig. 2c). Some of the increased sealing has occurred within the existing urban area (in 1984), indicating that Odense has been experiencing both growth and densification during the period of 1984-2014. Results are shown only for those parts of the city which are currently connected to the urban drainage system, which comprises the majority of the urban area.

\subsection{Exposure to flooding due to land cover changes and climate}

Figures 3 and 4 compiles the results of 30 simulations of urban flooding in Odense, varying the land cover (1984 vs. 2014), the climatic conditions (present day conditions, RCP 4.5 and RCP8.5 climate change scenarios) and the severity of the event (from RP5 to RP100) as outlined above.

In general we see that results for the RCP8.5 climate change scenario for 2071-2100 using the estimate of urban land cover from 2014 clearly stands out (Fig. 3). Whereas the total area flooded in most cases scale approximately linearly with the severity of the extreme precipitation event, in this case the scaling exhibits more of an exponential behaviour. We also find that the effect of increases to IS in terms of the total area flooded increases with the intensity of extreme precipitation and therefore also with the degree of climate change. In the case of Odense the impact of the observed 
change in urban land cover from 1984-2014 roughly compares to the impacts of climate change under the RCP4.5 scenario.

Our results indicate that a change in absolute imperviousness of $19 \%(32 \rightarrow 51 \%)$ during 1984-2014 has increased the overall flood extent during extreme precipitation by between 6 and $26 \%$ under current climatic conditions (Fig. 4). If a similar change in imperviousness took place under climate change conditions as expected in the RCP8.5 scenario this would result in an increase in overall flood extent of 21-36\%. Conversely, in a RCP8.5 scenario the exposure to flooding increases by $84-104 \%$ and $70-85 \%$, respectively, under current (2014) and historical (1984) levels of imperviousness. The combined effect of both land cover changes and climate changes increases the urban flood vulnerability by as much as $112-152 \%$ (moving from lowest to highest line in Fig. 3). From the perspective of climate change adaptation this clearly demonstrates quantitatively the effect of pervious surfaces as measures for reducing flood exposure. Conceptually, if measures where implemented reducing overall imperviousness by $19 \%$ (same as the increase in the period 1984-2014) flood exposure would decrease by 6-21\% under current climate and by 13-24\% (RCP4.5) and 17-27\% (RCP8.5) under future climatic conditions.

\section{Discussion}

In this research we demonstrate the applicability of a combined methodology for investigating the exposure of cities to pluvial flooding due to changes in the urban land covers (IS fractions) and climate. Whereas similar modelling work are carried out for most European cities and often using flood models of much higher complexity for the purpose of e.g. urban drainage design and cloudburst management, the analytical framework presented here is particularly suited for large-scale mapping of cities' vulnerability to climate change. Thus, the combination of remote sensing estimates with an easily customizable flood modelling approach principally makes it feasible to create improved maps, which takes into account past, present and future urban development as well as climate change in a consistent manner, which is transferable across cities and countries. Arguably, this may prove an important tool for policy-makers in facilitating urban adaptation to climate change at the European level (EU and EEA, 2012).

The methods described here for the urban land cover change analysis and flood modelling along with state of the art results from recent downscaling exercises and extreme value analysis of climate projections are well-described in literature. For example previous studies have shown that the amount in impervious surfaces strongly influences total and peak discharge, daily stream flows, run-off volumes and the hydrological response time during medium/high- intensity precipitation events (Jennings and Jarnagin, 2002; Chormanski et al., 2008; Verbeiren et al., 2013).

The method applied to quantify changes to IS is sensitive towards the presence of areas of bare soil. If large areas of bare soil were present within the urban area in either 1984 or 2014 it could result in misclassifications for those areas. However, as bare soil is only marginally present within most urban areas in Europe, including Denmark, we assume this not to have a large influence on the output of the Odense analyses, although this might not be true for all cities.

The uncertainty associated with climate change projections and with different downscaling methods is well documented (Frei et al., 2006; IPCC, 2014; Sunyer et al., 2014). As a result the derived climate factors for precipitation extremes may exhibit large variations even within the same climate scenario. Adopting a conservative approach we have in the current study used a set of climate factors for our design precipitation time series based on multiple model runs, which represents the "middle of the road" (Arnbjerg-Nielsen et al., 2015). Arguably, if used for adaptation planning one could instead decide to focus on best- and/or worst-case scenarios for robustness and economic considerations.

The flood model used in this study does not include a module for spatial representation of the drainage system in Odense, and the geographical location of surface flooding may therefore be inaccurate for some locations due to inconsistent dimensioning, since the actual drainage system in practice is not likely to be perfectly dimensioned according to a 5-year rainfall event for all locations. Evidently, this choice makes the model easily transferable to other cities at the cost of precision. When neglecting the sewage system, errors are introduced to the flood extents though these effects may be assumed to be localized and their significance to decrease with more extreme rain events (Paludan et al., 2012). Likewise, the use of a rather coarse DEM ( $25 \mathrm{~m}$ resolution) does not allow for identification of highly localised water flows and related flooding within urban areas (Villanueva et al., 2008). Finally, the total volume and extent of surface flooding (Fig. 3) must be interpreted with some caution and should be considered as a conservative estimate, since this assumes run-off from green areas to be negligible at any time during extreme precipitation (no saturation occurs). Changes in imperviousness have previously been found to be more pronounced for more frequent precipitation events (e.g. RP5) while only to a lesser degree affecting the hydrological response for less frequent events (RP100) (Hollis, 1975). The reason for this difference is that pervious surfaces saturates faster during very extreme events, and begin to behave as impervious areas rather quickly after the onset of the event. Conversely, the saturation time is commonly much longer during less extreme events. 


\section{Conclusions}

A combined remote sensing and flood modelling approach is developed and applied to quantify the influence of recent urban development and expected future climate change on the overall exposure of urban areas towards flooding from extreme precipitation. The results indicate that both changes to impervious surfaces and climate change are important in this respect. Our study suggests that the approach is applicable for quantifying and mapping the importance of these parameters towards changes in flood risk of European cities.

Acknowledgements. The authors would like to thank Nina Donna Sto. Domingo and Jakob Luchner from DHI for assisting in developing and running the flood model used in this study. We also gratefully acknowledge the "RiskChange" project funded by the Danish Council for Strategic Research for supporting this study and providing access to climate projections.

\section{References}

Arnbjerg-Nielsen, K., Madsen, H., and Mikkelsen, P. S.: Regional variation of extreme precipitation in Denmark - new version (1979-2005) (Skrift 28) (Regional Variation af ekstremregn i Danmark - ny bearbejdning (1979-2005) Skrift 28, IDA Spildevandskomiteen, 2006.

Arnbjerg-Nielsen, K., Leonardsen, L., and Madsen, H.: Evaluating climate change adaptation options for urban flooding based on new high-end emission scenario Regional Climate Model simulations, accepted, Clim. Res., 2015.

Arnold, C. L. and Gibbons, C. J.: Impervious Surface Coverage: The Emergence of a Key Environmental Indicator, J. Am. Plann. Assoc., 62, 243-258, doi:10.1080/01944369608975688, 1996.

Bauer, M. E., Loffelholz, B. C., and Wilson, B.: Estimating and mapping impervious surface area by regression analysis of Landsat imagery, in: Remote Sensing of Impervious Surfaces, CRC Press, Boca Raton, Florida, p. 454, 2008.

Chang, H. and Franczyk, J.: Climate Change, Land-Use Change, and Floods: Toward an Integrated Assessment, Geogr. Compass, 2, 1549-1579, doi:10.1111/j.1749-8198.2008.00136.x, 2008.

Chormanski, J., Van De Voorde, T., De Roeck, T., Batelaan, O., and Canters, F.: Improving distributed run-off prediction in urbanized catchments with remote sensing based estimates of impervious surface cover, Sensors, 8, 910-932, 2008.

European Union, European Environment Agency (EU and EEA): Urban adaptation to climate change in Europe: challenges and opportunities for cities together with supportive national and $\mathrm{Eu}-$ ropean policies, EUR-OP, Copenhagen, 143 pp., EEA Report No 2/2012, Luxembourg, 2012.

Field, C. B., Barros, V., Stocker, T. F., Qin, D., Dokken, D. J., Ebi, K. L., Mastrandrea, M. D., Mach, K. J., Plattner, G.-K., Allen, S. K., Tignor, M., and Midgley, P. M.: Managing the Risks of Extreme Events and Disasters to Advance Climate Change Adaption. A Special Report of Working Groups I and II of the Intergovernmental Panel on Climate Change, Cambridge University Press, New York, 582 pp., 2012.
Frei, C., Schöll, R., Fukutome, S., Schmidli, J., and Vidale, P. L.: Future change of precipitation extremes in Europe: Intercomparison of scenarios from regional climate models, J. Geophys. Res., 111, D06105, doi:10.1029/2005JD005965, 2006.

Gregersen, I. B., Sørup, H. J. D., Madsen, H., Rosbjerg, D., Mikkelsen, P. S., and Arnbjerg-Nielsen, K.: Assessing future climatic changes of rainfall extremes at small spatio-temporal scales, Clim. Change, 118, 783-797, doi:10.1007/s10584-0120669-0, 2013.

Gregersen, I. B., Madsen, H., Linde, J. J., and Arnbjerg-Nielsen, $\mathrm{K}$.: Updated climate factors and rain intensities for dimensioning (Skrift nr. 30) (Opdaterede klimafaktorer og dimensionsgivende regnintensiteter (Skrift nr. 30)), Spildevandskommiteen, 2014.

Hollis, G. E.: The effect of urbanization on floods of different recurrence interval, Water Resour. Res. 11, 431-435, doi:10.1029/WR011i003p00431, 1975.

IDA: CDS rain calculator, available at: http://ida.dk/sites/prod. ida.dk/files/regionalregnraekke_ver_4_0.xls (2 February 2015), 2014.

IPCC: Annex II: Climate System Scenario Tables, edited by: Prather, M., Flato, G., Friedlingstein, P., Jones, C., Lamarque, J.F., Liao, H., and Rasch, P., in: Climate Change 2013: The Physical Science Basis. Contribution of Working Group I to the Fifth Assessment Report of the Intergovernmental Panel on Climate Change, edited by: Stocker, T. F., Qin, D., Plattner, G.-K., Tignor, M., Allen, S. K., Boschung, J., Nauels, A., Xia, Y., Bex, V., Midgley, P. M., Cambridge University Press, Cambridge, United Kingdom and New York, NY, USA

Jennings, D. B. and Jarnagin, S. T.: Changes in anthropogenic impervious surfaces, precipitation and daily streamflow discharge: a historical perspective in a mid-atlantic subwatershed, Landsc. Ecol., 17, 471-489, 2002.

Leandro, J., Chen, A. S., Djordjević, S., and Savić, D. A.: Comparison of 1D/1D and 1D/2D Coupled (Sewer/Surface) Hydraulic Models for Urban Flood Simulation, J. Hydraul. Eng., 135, 495504, doi:10.1061/(ASCE)HY.1943-7900.0000037, 2009.

Maksimović, Č., Prodanović, D., Boonya-Aroonnet, S., Leitão, J. P., Djordjević, S., and Allitt, R.: Overland flow and pathway analysis for modelling of urban pluvial flooding, J. Hydraul. Res., 47, 512-523, doi:10.1080/00221686.2009.9522027, 2009.

Mark, O., Weesakul, S., Apirumanekul, C., Aroonnet, S. B., and Djordjević, S.: Potential and limitations of 1D modelling of urban flooding, J. Hydrol., 299, 284-299, doi:10.1016/j.jhydrol.2004.08.014, 2004.

Maule, C. F., Mayer, S., Sobolowski, S., and Christensen, O. B.: Background information on the RiskChange simulations by BCCR and DMI, Danish Climate Centre Report 14-05, DMI, 2014.

Meinshausen, M., Smith, S. J., Calvin, K., Daniel, J. S., Kainuma, M. L. T., Lamarque, J.-F., Matsumoto, K., Montzka, S. A., Raper, S. C. B., Riahi, K., Thomson, A., Velders, G. J. M., and van Vuuren, D. P. P.: The RCP greenhouse gas concentrations and their extensions from 1765 to 2300 , Clim. Change, 109, 213241, doi:10.1007/s10584-011-0156-z, 2011.

MIKE by DHI, available at: http://mikebydhi.com (last access: 18 January 2014), 2014.

Paludan, B., Nielsen, N. H., Brink-Kjær, A., Jense, L. N., Linde, J. J., and Mark, O.: The Climate Cookbook - 2nd edition, 
Forsknings- og udredningsprojekt nr. 19 Danva ISBN 978-8792651-04-4, 1-83, 2012.

Skougaard Kaspersen, P., Fensholt, R., and Drews, M.: Estimating impervious surface fractions for urban areas in Europe using Landsat 8 vegetation indices, submitted, Remote Sens., 2015.

Sunyer, M. A., Gregersen, I. B., Rosbjerg, D., Madsen, H., Luchner, J., and Arnbjerg-Nielsen, K.: Comparison of different statistical downscaling methods to estimate changes in hourly extreme precipitation using RCM projections from ENSEMBLES: STATISTICAL DOWNSCALING METHODS FOR EXTREME PRECIPITATION, Int. J. Climatol., doi:10.1002/joc.4138, 2014.

TUFLOW: TUFLOW - Flood and Coastal Simulation software, available at: http://www.tuflow.com (last access: 18 January 2014), 2014.

Van der Linden, P. and Mitchell, J.: ENSEMBLES: Climate Change and its Impacts: Summary of research and results from the ENSEMBLES project. Met Office Hadley Centre, FitzRoy Road, Exeter EX1 3PB, UK, 2009.
Verbeiren, B., Van De Voorde, T., Canters, F., Binard, M., Cornet, Y., and Batelaan, O.: Assessing urbanisation effects on rainfall-runoff using a remote sensing supported modelling strategy, Int. J. Appl. Earth Obs. sGeoinf., 21, 92-102, doi:10.1016/j.jag.2012.08.011, 2013.

Villanueva, I., Pender, G., Lin, B., Mason, D. C., Falconer, R. A., Neelz, S., Crossley, A. J., Bates, P. D., Liang, D., Hunter, N. M., Wright, N. G., and Waller, S.: Benchmarking 2D hydraulic models for urban floodin, Proc. ICE - Water Management, 161, 1330, doi:10.1680/wama.2008.161.1.13, 2008.

Willems, P.: Impacts of climate change on rainfall extremes and urban drainage systems, IWA, London, 226 pp., 2012. 